\title{
Third Annual Report
}

\section{Influences of Flow Transients and Porous Medium Heterogeneity on Colloid-Associated Contaminant Transport in the Vadose Zone}

\author{
Award Numbers: DE-FG07-02ER63492 (Yale) and DE-FG07-02ER63491 (Colorado) \\ Project ID: 86900 \\ James Saiers, Yale University (PI) \\ Joseph Ryan, University of Colorado (Co-PI)
}

\section{Background}

This report summarizes research conducted during Year 3 of a project that extends through 31 December 2005. The work described below is part of a collaborative effort funded by separate awards to Yale University (lead institution) and the University of Colorado.

\section{$\underline{\text { Research Objectives }}$}

Our research is guided by an EMSP objective to improve conceptual and predictive models of contaminant movement in vadose-zone environments. As described in the report National Roadmap for Vadose-Zone Science and Technology [DOE, 2001], soil-water colloids are capable of adsorbing contaminants, such as radionuclides and metals, and facilitating their migration through the vadose zone and towards groundwater reservoirs. Our research centers on advancing understanding of this phenomenon. In particular, we are combining mathematical modeling with laboratory experimentation at pore and column scales to

1. elucidate the effects of porewater-flow transients on colloid mobilization in unsaturated porous media;

2. explore the sensitivity of colloid deposition rates to changes in porewater chemistry and colloid mineralogy;

3. develop mathematical models appropriate for simulating colloid mobilization, transport, and deposition under both steady-flow and transient-flow conditions;

4. identify mechanisms that govern mineral-colloid mobilization and deposition in unsaturated porous media;

5. quantify the effects of mineral-grain geometry and surface roughness on colloidfiltration rates; and

6. evaluate the influences of colloids on the transport of strontium and cesium (i.e., DOEcontaminants-of-concern) through soils and sediments.

\section{$\underline{\text { Research Progress }}$}

In the Years 1 and 2 of the project, we determined the role of flow transients in colloid mobilization (Objective 1), examined the influences of $\mathrm{pH}$ and clay mineralogy on colloid deposition rates (Objective 2), and developed phenomenological models capable of describing colloid mobilization, transport, and deposition under steady and transient-flow conditions 
(Objective 3). During the first nine months of Year 3, we have focused on accomplishing Objectives $4-6$.

Part of our work in Year 3 involved testing our inferences on mechanisms that govern colloid deposition and mobilization through analysis of pore-scale visualization experiments (Objective 4). In these visualization experiments, a transparent flow cell packed with a thin layer of unsaturated sand was placed on a stage of an inverted microscope to permit direct observation of deposition and mobilization. Our results show that multiple mechanisms contribute to colloid deposition. Insular air bubbles scavenged colloids, which is consistent with results of

(a)

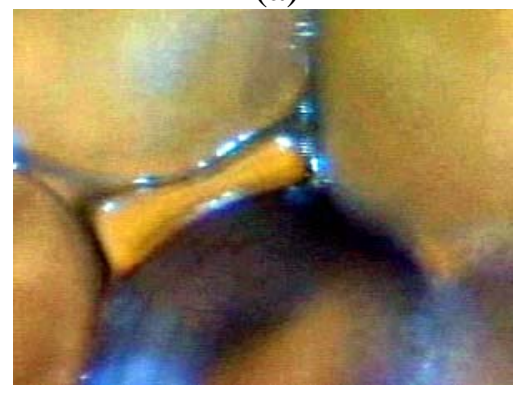

(b)

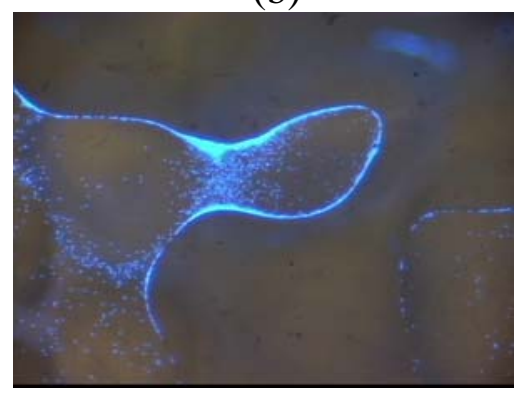

Figure 1. Pore-scale visualization of colloid immobilization: (a) colloids retained within thin films and pendular rings of a partially saturated pore) and (b) colloids stored within stagnant-water regions that branch off from mobile-water regions (note colloid accumulation along perimeter of stagnant water zone at air-water boundary. pore (air occupies the center of the

experiments conducted with etched micromodels [Wan and Wilson, 1994; Sirivithayapakorn and Keller, 2003]. Other deposited colloids were held within thin films of water that stretched between pendular rings of unsaturated pores (Figure 1a). These observations confirm previous speculation of the significance of film straining in influencing colloid mobility [Wan and Tokunaga, 1997; Lenhart and Saiers, 2002; Saiers and Lenhart, 2003]. Colloids also were effectively immobilized upon entry into zones of stagnant water (Figure 1b). This concept of stagnant-water zones has long been used to account for the storage of solutes, but, with very few exceptions [Gamerdinger and Kaplan, 2001; Cherrey et al., 2003], has been ignored in descriptions of colloid transport and, prior to our work, no confirmatory evidence for stagnantwater storage of colloids existed.

The visualization experiments were especially useful in yielding insight into the mechanism that control colloid mobilization. During transient porewater flow, characterized by temporal increases in moisture content, two mechanisms dominated the mobilization response. Film-strained colloids were released as the films were abruptly eliminated when partially saturated pores filled spontaneously with water. Porous-medium imbibition also promoted the release of colloids held within stagnant-water zones as water invaded air-filled regions of the porous medium and fragmented stagnant-water zones reconnected to areas of bulk fluid flow. The increases in flow rate that accompanied the moisturecontent increases during the transient-flow experiments did not shear detectable quantities of colloids from the surfaces of the sand grains or insular air bubbles. Knowledge gained from these experiments is currently being used to refine the structure of our mathematical models that account for coupled transient porewater flow, colloid mobilization, and transport.

Even in our well-controlled laboratory systems, the porous medium is non-ideal, consisting of non-spherical mineral grains with considerable surface roughness. Published theoretical descriptions of colloid filtration, which were developed for water-saturated systems, are not designed to account for these non-idealities. One aspect of our ongoing research is devoted to modifying colloid-filtration theory to account for non-idealities associated with real geologic materials (Objective 5). Through statistical analysis of pore-scale simulations of 
laminar flow and convective-diffusive transport, we have derived new correlation equations that express colloid-filtration rates in terms of porewater velocity, colloid size, and measurable indices that quantify mineral-grain shape and surface roughness. Our current results are only appropriate for water-saturated systems; however, we are extending this analysis to account for complexities associated with waterunsaturated porous media. We believe that this work will facilitate a shift from empirical descriptions of colloid deposition in the vadose zone to one in which colloid deposition can be predicted on the basis of measurable system properties.

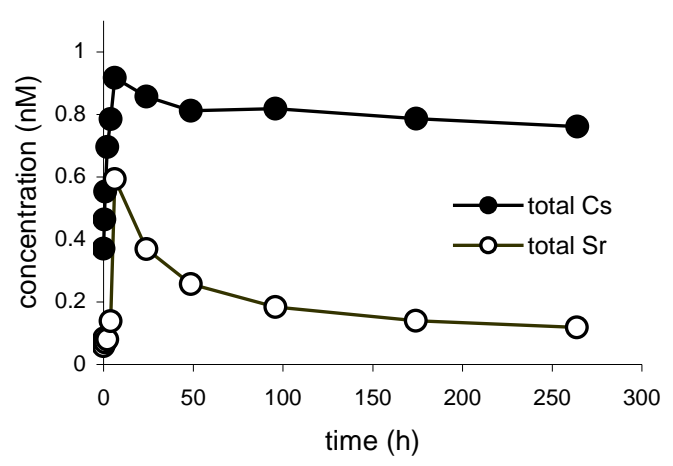

Figure 2. Total concentrations of ${ }^{137} \mathrm{Cs}$ and ${ }^{90} \mathrm{Sr}$ in the effluent of a recirculating saturated quartz sand column. Cs transport was facilitated by illite to a greater extent than Sr transport because Cs desorbed from the illite about three times slower than Sr.

One of the key criteria for facilitated transport is that desorption of the contaminants from the colloids is slow relative to the transport time. Only if desorption is slow can colloids carry contaminants ahead of a contaminant plume [Ryan and Elimelech, 1996; Roy and Dzombak, 1998]. While this criterion is well known [Vilks et al., 1993], its importance had only been inferred from field evidence and models [Roy and Dzombak, 1998]. To test this criterion, we examined the facilitated transport of $\mathrm{Cs}^{+}$and $\mathrm{Sr}^{2+}$ by illite colloids in saturated flow-through columns and recirculating columns containing quartz sand (Objective 6). Using the Saiers and Hornberger [1999] model of colloid-facilitated transport, we were able to show that desorption of strontium ions from the illite colloids was about three times as fast as that of the cesium. The extent of colloid-facilitated transport depended on the solution ionic strength and the cation/illite ratio. Slow desorption of cesium from illite was particularly evident at a very low $\mathrm{Cs}^{+} /$illite ratio $\left(10^{-8} \mathrm{~mol} \mathrm{~g}^{-1}\right)$ in the recirculating column (Figure 2). The cation desorption kinetics parameters are now being used to evaluate cesium and strontium transport in unsaturated columns of homogeneous and physically heterogeneous quartz sand.

\section{Peer-Reviewed Publications and Presentations of Public Record}

Findings from this research have been reported in six manuscripts that have been published or submitted for publication (Box 1). Three more manuscripts are in preparation and will be submitted before the end summer 2005. We also have presented our research at numerous scientific conferences in the U.S. and Europe (Box 2).

\section{Planned Research Activities}

During the remaining six months of the project, we intend to focus on the role of porousmedium heterogeneity on the unsaturated transport of colloids and colloid-associated contaminants (Figure 3). We have begun to examine the transport of colloids through unsaturated columns containing a single structured heterogeneity. Our preliminary results demonstrate that, even in this ideal system, nonuniformity in moisture content produces complex effects on colloid transport and deposition. We plan to extend this work by investigating the movement of colloids and colloid-associated cesium and strontium through intact cores containing structured heterogeneity. These data will be the first of their kind and will be critical 


\section{to the continued refinement of our models for the transport of colloid-bound contaminants through vadose-zone environments at DOE sites.}

\section{Box 1. Peer-reviewed papers attributed to EMSP grants: published, in review, and in preparation.}

DeNovio, N.M., J.E. Saiers, and J.N. Ryan, 2004. Colloid movement in unsaturated porous media: Recent advances and future directions. Vadose Zone Journal, 3: 338-351.

Gao, B., J.E. Saiers, and J.N. Ryan, 2004. Deposition and mobilization of clay colloids in unsaturated porous media. Water Resources Research, 40(8), W08602, doi: 10.1029/2004WR003189.

Saiers, J.E., G.M. Hornberger, D.B. Gower, and J.S. Herman, 2003. The role of moving air-water interfaces in colloid mobilization within the vadose zone. Geophysical Research Letters, 30(21), 2083, doi: 10.1029/2003GL018418.

DeNovio, N.M. and J.N. Ryan, in review. Using particle size to evaluate particle mobilization mechanisms in unsaturated sand columns during simulated rainfall. Submitted to Environmental Science \& Technology.

Gao, B., J.E. Saiers, and J.N. Ryan, in review. Pore-scale mechanisms of colloid deposition and mobilization during steady and transient flow through unsaturated granular media. Submitted to Water Resources Research.

DeNovio, N.M., J.N. Ryan, J.E. Saiers, and J.F Ranville, in review. Mobilization of metals associated with colloids and organic matter by simulated rainfall in intact cores of a metal-contaminated soil. Submitted to Environmental Science \&Technology.

DeNovio, N.M., J.N. Ryan, and J.E. Saiers, in preparation. Mobilization of colloids and organic matter by simulated rainfall in intact cores of a metal-contaminated soil. Planned submission to Water Resources Research in July, 2005.

Saiers, J.E., B. Gao, and J.N. Ryan, in preparation. How do mineral-grain shape and surface roughness influence colloidfiltration rates? Planned submission to Geophysical Research Letters in July 2005.

Turner, N., J.N. Ryan, and J.E. Saiers, in preparation. Kinetics of cesium and strontium desorption from clay mineral colloids in a saturated quartz porous medium. Planned submission to Environmental Science \& Technology in September, 2005.

\section{Box 2. Presentations of research attributed to EMSP grants.}

Gao, B. and J.E. Saiers, 2004. Influence of $\mathrm{pH}$ on deposition and mobilization of clay colloids in unsaturated porous media. Proceedings of the $78^{\text {th }}$ ACS Colloid and Surface Science Symposium, New Haven, CT, June 20 - June 23, 2004.

Ryan, J.N. and N.M. DeNovio, 2005. Effect of simulated rainfall on the transport of metals, organic matter, and colloids in a metal-contaminated flood plain soil. International Workshop on Colloids and Colloid-Mediated Transport of Contaminants in Soils, Bad Herrenalb, Germany, June 19-22, 2005 (Invited).

Saiers, J.E., B. Gao, and J.N. Ryan, 2005. Colloid deposition and mobilization mechanisms in unsaturated porous media during steady and transient flow. To be presented at the General Assembly of the European Geosciences Union, Vienna, Austria, April 25 - April 29, 2005 (Invited).

Saiers, J.E., B. Gao, and J.N. Ryan, 2004a. Visualization of colloid deposition and mobilization during unsteady and steady porewater flow through unsaturated porous media. Fall Meeting of the American Geophysical Union. San Francisco, CA, December 13 - December 17, 2004 (Invited).

Saiers, J.E., J.J. Lenhart, and B. Gao, 2004b. Colloid mobilization, transport, and deposition in unsaturated porous media. Proceedings of the $227^{\text {th }}$ ACS National Meeting, Anaheim, CA, March 28-April 1, 2004 (Invited).

Turner, N.B., J.N. Ryan, and J.E. Saiers, 2005. Effect of cation desorption kinetics on the colloid-facilitated transport of cesium and strontium. Proceedings of the $229^{\text {th }}$ ACS National Meeting, San Diego, CA, March 13-17, 2005. 


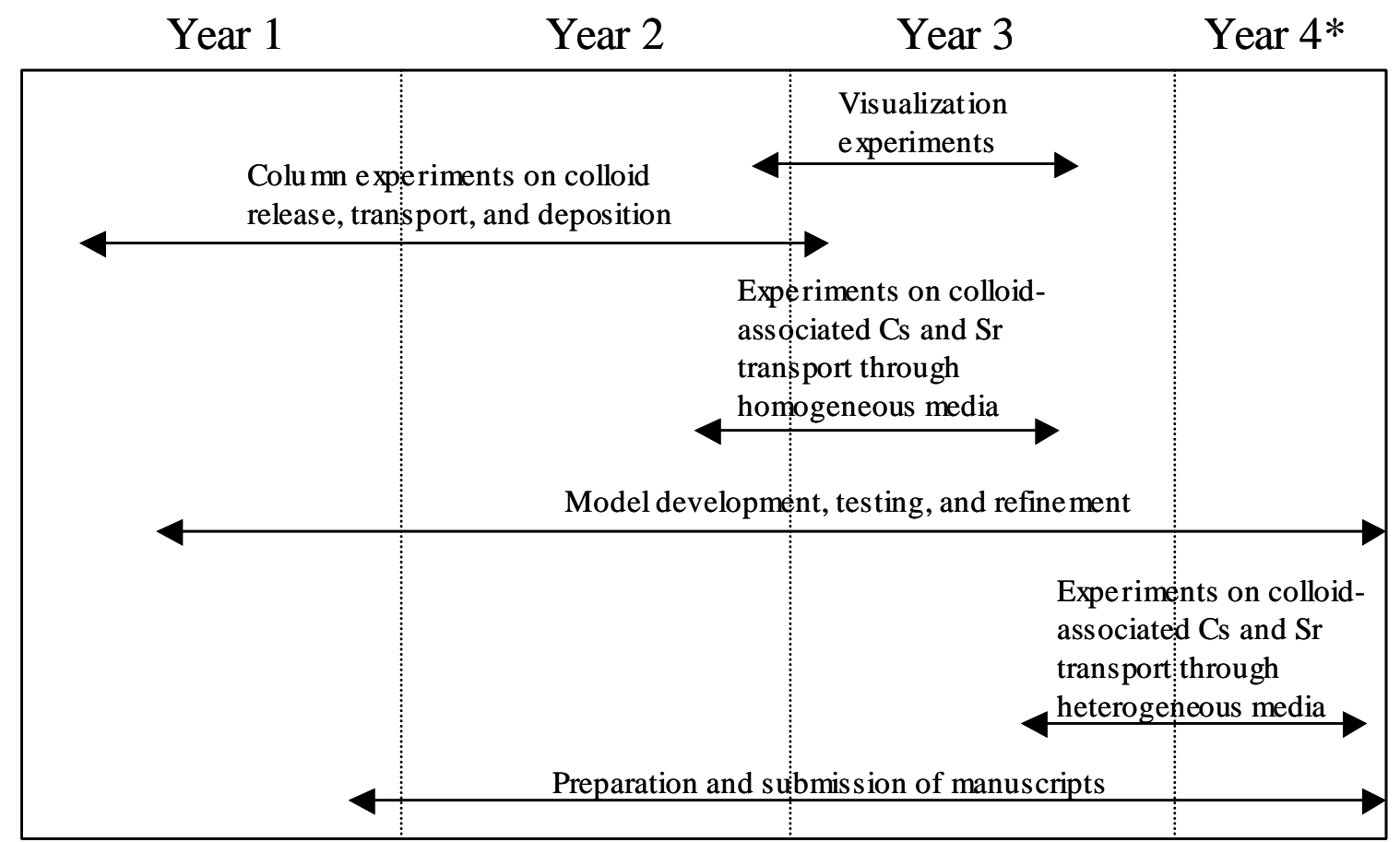

*We have secured a 3.5 month no-cost extension, which increases the project duration to 39.5 months.

Figure 3. Timeline for research activities. 


\section{$\underline{\text { References }}$}

Cherrey, K., M. Flury, and J. Harsh, Nitrate and colloid transport through coarse Hanford sediments under steady state, variably saturated flow, Water Resources Research, 39, 1165, doi: 10.1029/2002WR001944, 2003.

DOE, A National Roadmap for the Vadose Zone Science \& Technology. DOE/ID-10871, Washington, DC, 2001.

Gamerdinger, A.P. and D.I. Kaplan, Physical and chemical determinants of colloid transport and deposition in water-unsaturated sand and Yucca Mountain tuff material, Environmental Science and Technology, 35, 2497-2504, 2001.

Lenhart, J.J. and J.E. Saiers, Transport of silica colloids through unsaturated porous media: Experimental results and model comparisons, Environmental Science and Technology, 36, 769-777, 2002.

Roy, S.B. and D.A. Dzombak, Sorption nonequilibrium effects on colloid-enhanced transport of hydrophobic organic compounds in porous media, Journal of Contaminant Hydrology, 30, 179-200, 1998.

Ryan, J.N. and M. Elimelech, Colloid mobilization and transport in groundwater, Colloids and Surfaces A: Physicochemical Engineering Aspects, 107, 1-52, 1996.

Saiers, J.E. and G.M. Hornberger, The influence of ionic strength on the facilitated transport of cesium by kaolinite colloids, Water Resources Research, 35 (6), 1713-1727, 1999.

Saiers, J.E. and J.J. Lenhart, Ionic-strength effects on colloid transport and interfacial reactions in partially saturated porous media, Water Resources Research, 39 (9), 1256, doi:10.1029/2002WR001887, 2003.

Sirivithayapakorn, S. and A. Keller, Transport of colloids in unsaturated porous media: a porescale observation of processes during the dissolution of the air-water interface, Water Resources Research, 39, 1346, doi: 10.1029/2003WR002487, 2003.

Vilks, P.J., J. Cramer, D.B. Bachinski, D.C. Doern, and H.G. Miller, Studies of colloids and suspended particles, Cigar Lake uranium deposit, Saskatchewan, Canada, Applied Geochemistry, 8, 605-616, 1993.

Wan, J. and T.K. Tokunaga, Film straining of colloids in unsaturated porous media: conceptual model and experimental testing, Environmental Science and Technology, 31, 2413-2420, 1997.

Wan, J. and J.L. Wilson, Visualization of the role of the gas-water interface on the fate and transport of colloids in porous media, Water Resources Research, 30 (1), 11-23, 1994. 